\title{
Risk Factors for Pulmonary Arterial Hypertension in Children and Young Adults
}

\author{
Estelle Naumburg, MD, PhD, ${ }^{1,2 \star}$ Lars Söderström, $\mathrm{MSc}^{2}$ Daniel Huber, ${ }^{2}{ }^{2}$, and Inge Axelsson, MD, PhD ${ }^{2}$
}

\begin{abstract}
Summary. Objectives: Pulmonary hypertension $(\mathrm{PH})$ has been linked to preterm birth explained by congenital heart defects and pulmonary diseases. Working hypothesis: Other factors may influence the risk of $\mathrm{PH}$ among adolescences and children born premature. Study design: This national registry-based study assess risk of $\mathrm{PH}$ following premature birth adjusted for known risk factors. Patient-subject selection and methodology: All cases born 1993-2010, identified by diagnostic codes applicable to $\mathrm{PH}$ and retrieved from the Swedish Registry of Congenital Heart Disease $(N=67)$. Six controls were randomly selected and matched to each case by year of birth and hospital by the Swedish Medical Birth Register $(\mathrm{N}=402)$. Maternal and infant data related to preterm birth, pulmonary diseases, and congenital defects were retrieved. The association between preterm birth and pulmonary hypertension was calculated by conditional logistic regression taking into account potential confounding factors. Results: One third of the cases and seven percent of the controls were born preterm in our study. Preterm birth was associated with $\mathrm{PH}, \mathrm{OR}=8.46(95 \% \mathrm{Cl} 2.97-24.10)(P<0.0001)$ even after adjusting for confounding factors. Other factors, such as acute pulmonary diseases, congenital heart defects, congenital diaphragm herniation, and chromosomal disorders were also associated with $\mathrm{PH}$ in the multivariate analysis. Conclusions: Children and young adults born preterm are known to have an increased risk of $\mathrm{PH}$, previously explained by congenital heart defects and pulmonary diseases. By adjusting for such factors, our study indicates that new factors may play a role in the risk of developing $\mathrm{PH}$ among children born preterm. Pediatr Pulmonol. 2017;52:636-641. @ @ 2016 Wiley Periodicals, Inc.
\end{abstract}

Key words: bronchopulmonary dysplasia; chronic lung disease of the newborn; congenital diaphragm herniation; preterm birth; pulmonary hypertension.

Funding source: none reported.

\section{INTRODUCTION}

The association between preterm birth and pulmonary hypertension $(\mathrm{PH})$ has previously been explained by congenital heart disease (CHD), and chronic lung disease (CLD) such as bronchopulmonary dysplasia (BPD). ${ }^{1}$

Infants with extremely low birthweights and/or established BPD are at high risk of infant PH as well as long-term pulmonary morbidity. Infants born in different eras of neonatology show similar long-term impairment in lung function, airway obstruction, structural abnormalities of the gas transfer and pulmonary function., ${ }^{2,3}$ However, in a recent study we found that premature birth in the pre-surfactant era was associated with an increased risk of adult $\mathrm{PH}$ even after adjustments were made for these risk factors. ${ }^{4}$ Our working hypothesis was that $\mathrm{PH}$ was associated with premature birth also in the postsurfactant era.

The aim of this present population-based registry study was to assess the risk of $\mathrm{PH}$ following exposure to preterm birth during a time when external surfactant was in regular use, and adjusting for known risk factors.

\section{METHODS}

\section{Study Population}

All live born infants born between 1993 and 2010 who were registered in the population-based Swedish Medical

\footnotetext{
${ }^{1}$ Department of Clinical Science, Paediatrics, Umeå University, Umeå, Sweden

${ }^{2}$ Östersund Hospital, Unit of Research, Education and Development, Östersund, Sweden.

Conflict of interest: None.

${ }^{*}$ Correspondence to: Estelle Naumburg, MD, PhD, Department of Pediatric, Östersund Hospital, SE-831 83 Östersund Sweden.

E-mail: estelle.naumburg@umu.se
}

Received 23 May 2016; Revised 5 September 2016; Accepted 5 October 2016.

DOI 10.1002/ppul.23633

Published online 1 November 2016 in Wiley Online Library

(wileyonlinelibrary.com). 
Birth Register were included. Cases were retrieved from the Swedish Registry of Congenital Heart Disease (SWEDCON), which is the pediatric national based register for CHD (SWEDCON, http://www.ucr.uu.se/ swedcon/). Cases were identified by diagnostic codes applicable to pulmonary hypertension; European Pediatric Cardiology Codes (EPCC-codes): 10.13.01, 10.13.02, 10.13.07, 10.13.08, 10.13.20, 10.15.1 comparable to the International Classification of Diseases (ICD 10-codes): I27.0, I27.2, P29.3B.$^{5,6}$ Overall, 67 cases were included in the study (53.3\% male). Six controls were matched to each case by year of birth and hospital. Controls were randomly selected by the Swedish Medical Birth Register staff. Inclusion criteria for cases as well for controls were to be born in Sweden during the study period and registered in the Swedish Medical Birth Register. There were no exclusion criteria other than not diagnosed with pulmonary hypertension in child- or adulthood for controls.

\section{The Swedish Medical Birth Register}

The Swedish Medical Birth Register was established in 1973 and it uses a standardized set of medical records and is held by the Swedish National Board of Health and Welfare. Registration starts on the first visit to the antenatal clinic and is completed when the mother and the newborn infant are discharged from the hospital. The records are used by all antenatal clinics, delivery units, and during newborn examinations. Information on more than $99 \%$ of all births in Sweden is included. Information on maternal demographic data, reproductive history, maternal smoking habits, the pregnancy, the delivery, and neonatal factors is included for all births. ${ }^{7}$

\section{National Registration Number}

In Sweden, a unique 12-digit national registration number is assigned to each resident and used in official population-based registers. This makes it possible to

\begin{tabular}{|ll|}
\hline \multicolumn{2}{l|}{ ABBREVIATIONS } \\
APA & Appropriate for gestational age \\
BPD & Bronchopulmonary dysplasia \\
CHD & Congenital heart disease \\
CPAP & Continuous positive airway pressure \\
CI & Confidence interval \\
CLD & Chronic lung disease \\
EPCC & European Pediatric Cardiology Codes \\
ICD 10 codes & International Classification of Diseases (ICD 10 \\
& codes) \\
LGA & Large for gestational age \\
OR & Odds ratio \\
PH & Pulmonary arterial hypertension \\
PPHN & Persistent pulmonary hypertension as neonate \\
SD & Standard deviations \\
SGA & Small for gestational age \\
SWEDCON & Swedish Congential Heart Defect Register \\
& \\
\hline
\end{tabular}

identify individuals, collect certain information from registers and link information between different registers.

This unique personal identification number was used to retrieve information on maternal and neonatal characteristics for all cases and controls from the SWEDCON register and the Swedish Medical Birth Register.

\section{Exposure Data}

Data related to preterm birth, congenital heart defect, and pulmonary disease were retrieved from the Swedish Medical Birth Register. The following data were retrieved for maternal and pregnancy information: maternal age, chronic diseases (such as kidney failure, celiac disease, epilepsy, ulcerative colitis, diabetes mellitus, asthma, and systemic lupus erythematosus), reproductive history, diseases during pregnancy, mode of delivery (non-instrumental and instrumental vaginal delivery, emergency, and elective Caesarean section). The following information was retrieved for the cases and controls: gender, gestational age at birth, birthweight, and birth length and Apgar scores at 1 and $5 \mathrm{~min}$. Gestational age was estimated from the antenatal determination of gestational age by ultrasound and retrieved from the Swedish Medical Birth Register. Small for gestational age (SGA) was defined as a birthweight of more than two standard deviations (SD) below the mean birthweight for gestational age and sex according to the Swedish birthweight curve. Appropriate for gestational age (APA) was defined as a birthweight between -2 and +2 SD and large for gestational age (LGA) as a birthweight of more than two SD above the mean. Further, medical information on acute or chronic lung disease, BPD, persistent pulmonary hypertension of the newborn (PPHN), use of mechanical ventilation or CPAP, sepsis, or necrotizing enterocolitis (NEC) and congenital diaphragm herniation, congenital heart defects and chromosome abnormities was obtained.

Medical information was retrieved using the International Classification of Diseases ICD-9 or ICD-10 codes, and ICD-9 codes were manually transformed into ICD-10 codes and grouped for calculations.

\section{Statistical Methods}

The association between preterm birth prior to 37 weeks of gestation and $\mathrm{PH}$ was calculated by conditional logistic regression. Maximum-likelihood estimates of the odds ratio (OR) and 95\% confidence interval (CI), were obtained taking into account potential confounding factors. SAS version 9.4 (SAS Institute Inc., Cary, NC), was used to fit the conditional logistic model to our 1:6 matched casecontrol data. 


\section{Informed Consent}

This is a registry-based study. All children in the Swedish Registry of Congenital Heart Disease have communicated informed consent to the registry in sharing data for scientific purpose. The study was approved by the regional ethics committee, Umeå University (D2011-396-31M).

\section{RESULTS}

The study population consisted of children and young adults with $\mathrm{PH}(\mathrm{N}=67)$ who were individually matched with six controls $(\mathrm{N}=402)$, in total 469 individuals. The children were all born between 1993 and 2010. The median birth year was 2006 with an interquartile range (IQR) of 9 years. The diagnoses "pulmonary hypertension" and "primary pulmonary hypertension" (EPCC 10.13.01 and 10.13.02) were more common $(\mathrm{N}=62)$ than secondary hypertension (EPCC 10.13.20) $(\mathrm{N}=25)$ and Eisenmengar syndrome (EPCC 10.13.08) $(\mathrm{N}=1)$. Down syndrome was present in five infants. All types of chromosomal abnormities and syndromes, pulmonary disease, congenital diaphragm herniation, and other potential confounders are described in Table 1 and were used in the multivariable regression model.

In our study, $29(36 \%)$ of the cases and $29(7 \%)$ of the controls were born prior to 37 completed gestational weeks (Table 1). Maternal hypertension, preterm birth, SGA, acute pulmonary disease, mechanical ventilation and CPAP, congenital diaphragm herniation, $\mathrm{CHD}$, sepsis, or NEC and chromosomal abnormalities were all associated with $\mathrm{PH}$ in the univariate analysis (Table 2). Preterm birth was associated with $\mathrm{PH}, \mathrm{OR}=8.46$ $(95 \% \mathrm{CI}=2.97-24.10)$ even after adjusting for confounding factors (Table 3). Acute pulmonary diseases, congenital diaphragm herniation as well as congenital heart defect and chromosomal disorders and syndromes were also associated with $\mathrm{PH}$ after adjusting for confounding factors (Table 3 ).

\section{DISCUSSION}

Preterm birth was associated with an increased risk of PH among children and young adults in this national based register study. The risk did not alter after adjusting for known risk factors such as chronic pulmonary disease, congenital heart defects, congenital diaphragm herniation, or chromosomal abnormities and syndromes.

In a previous study, we found an increased risk of $\mathrm{PH}$ in adults born preterm. ${ }^{4}$ This study covered mainly the 1970s and 1980s, which was a period when surfactant was not in regular clinical use and is called the "pre-surfactant era." The first successful trial of endotracheal surfactant administration to preterm infants was performed in the 1980s and surfactant treatment was later proven to reduce
TABLE 1-Characteristics of the Study Population $(\mathrm{N}=469)$

\begin{tabular}{|c|c|c|c|c|c|}
\hline \multirow[b]{2}{*}{ Variable } & \multicolumn{2}{|c|}{ Cases (67) } & \multicolumn{2}{|c|}{$\begin{array}{l}\text { Controls } \\
\text { (402) }\end{array}$} & \multirow[b]{2}{*}{$P$-value } \\
\hline & $\mathrm{N}$ & $\%$ & $\mathrm{~N}$ & $\%$ & \\
\hline First child & 24 & 35.8 & 167 & 41.5 & 0.4217 \\
\hline $\begin{array}{l}\text { Gestational age }<36 \\
\text { weeks }\end{array}$ & 29 & 35.8 & 29 & 7.2 & $<0.0001$ \\
\hline Female gender & 32 & 47.8 & 187 & 46.5 & 0.8951 \\
\hline SGA & 6 & 9.0 & 10 & 2.5 & 0.0169 \\
\hline LGA & 4 & 6.0 & 14 & 3.5 & 0.3062 \\
\hline $\begin{array}{l}\text { Chronic pulmonary } \\
\text { disease }^{1}\end{array}$ & 15 & 22.8 & 1 & 0.2 & $<0.0001$ \\
\hline $\begin{array}{l}\text { Neonatal acute } \\
\text { pulmonary disease }\end{array}$ & 25 & 37.3 & 28 & 7.0 & $<0.0001$ \\
\hline $\mathrm{BPD}^{1}$ & 14 & 20.9 & 0 & 0 & $<0.0001$ \\
\hline PPHN in newborn & 25 & 37.3 & 2 & 0.5 & $<0.0001$ \\
\hline $\begin{array}{l}\text { Congenital defect (not } \\
\text { heart) }\end{array}$ & 5 & 7.5 & 1 & 0.2 & 0.0003 \\
\hline Congenital heart defect & 12 & 17.9 & 6 & 1.5 & $<0.0001$ \\
\hline \multirow{2}{*}{$\begin{array}{l}\text { Chromosomal } \\
\text { abnormalities }\end{array}$} & 6 & 9.0 & 1 & 0.2 & $<0.0001$ \\
\hline & Mean & SD & Mean & SD & \\
\hline Maternal age & 33.5 & 4.9 & 29.9 & 5.2 & 0.0161 \\
\hline Birth weight (grams) & 2368.0 & 1355.2 & 3509.6 & 636.6 & $<0.0001$ \\
\hline Apgar 1 & 6.6 & 2.8 & 8.7 & 1.1 & $<0.0001$ \\
\hline Apgar 5 & 8.1 & 2.2 & 9.7 & 0.9 & $<0.0001$ \\
\hline
\end{tabular}

${ }^{1}$ Infant with diagnosis "Chronic lung disease" $(\mathrm{N}=16)$ were also diagnosed with BPD $(\mathrm{N}=14)$.

the need for supplemental oxygen and ventilator support as well as the risk of neonatal death. Since the early 1990 s surfactant has been in clinical use in Sweden, and worldwide since the mid-1990s. ${ }^{8-10}$ In this study, we included children born during the "surfactant era" in Sweden. Along with surfactant, antenatal corticosteroid

TABLE 2-Risk of Pulmonary Hypertension

\begin{tabular}{lrrr}
\hline & \multicolumn{3}{c}{$95 \%$ CI } \\
\cline { 2 - 4 } Risk factor & OR & Lower & Upper \\
\hline Maternal age & 1.06 & 1.01 & 1.12 \\
Maternal hypertension & 5.24 & 1.89 & 14.29 \\
Maternal smoking & 0.33 & 0.12 & 0.85 \\
Gestational age $\leq 36$ weeks & 15.35 & 7.05 & 33.40 \\
Birth weight & 0.78 & 0.75 & 0.80 \\
Female gender & 1.05 & 0.62 & 1.79 \\
Small for gestational age & 3.96 & 1.33 & 11.88 \\
Acute pulmonary disease & 8.35 & 4.22 & 16.52 \\
Mechanichal ventilation/CPAP & 27.00 & 5.65 & 128.94 \\
Congenital diaphragm herniation & 30.00 & 3.35 & 268.30 \\
Congenital heart defect & 13.81 & 4.75 & 40.16 \\
Sepsis/NEC & 11.04 & 4.04 & 30.22 \\
Chromosomal abnormalities & 36.00 & 4.15 & 312.24 \\
\hline
\end{tabular}

Univariate logistic regression. 
TABLE 3-Risk of Pulmonary Hypertension

\begin{tabular}{lrrr}
\hline & \multicolumn{3}{c}{$95 \% \mathrm{CI}$} \\
\cline { 2 - 4 } Risk factor & \multicolumn{1}{c}{ OR } & Lower & Upper \\
\hline Maternal age & 1.08 & 1.01 & 1.58 \\
Acute pulmonary disease & 3.58 & 1.33 & 9.55 \\
Congenital diaphragm herniation & 94.26 & 6.58 & 999.99 \\
Congenital heart defect & 4.26 & 1.13 & 16.10 \\
Chromosome disorder & 22.47 & 1.44 & 351.28 \\
Gestational age $\leq 36$ weeks & 8.46 & 2.97 & 24.10 \\
\hline
\end{tabular}

Multiple logistic regression.

treatment of women at risk of preterm delivery has been in standard clinical treatment since the 1980s. Antenatal corticosteroids induce fetal pulmonary maturation and reduce the incidence of respiratory morbidity and mortality. ${ }^{11,12}$

The overall incidence of any form of acute lung disease in a newborn is approximately $3 \%$, and increases with decreasing gestational age and birthweight. ${ }^{13}$ Increased survival rates following preterm birth have been seen in Sweden and worldwide in recent decades. ${ }^{14}$ The use of surfactant, antenatal corticosteroids, and noninvasive mechanical ventilation strategies have shown to reduce neonatal respiratory disease and mortality, even despite a shift toward increasing numbers of preterm births. ${ }^{15}$

During the surfactant era, the clinical pattern of BPD changed toward smaller and more immature infants, compared to the pre-surfactant era. ${ }^{16,17}$ In this present study of children and young adults (5-23 years of age), preterm birth was five times more common among cases (35.8\%) compared to controls (7.2\%). Premature birth has been reported by others to be common among children with PH (14-21.8\%), and even more common when pulmonary disease is related to the PH-diagnosis. ${ }^{18,19} \mathrm{We}$ do not know why the prematurely born children among cases in our study are almost double as common as in other studies. However, the increasing survival rates after premature birth during the study periodin Sweden may have some impact. ${ }^{14}$

Several diagnoses associated with impaired pulmonary function were more common among cases than controls (Table 1). The "new bronchopulmonary dysplasia" has recently been described as originating from a multifactorial etiology, including high tidal volumes during mechanical ventilation, leading to hyperoxic and barotrauma induced inflammation, patent ductus arteriosus with volume overload, maternal chorioamnionitis, and genetic factors. ${ }^{20-22}$ Growth factors involved in alverolarization, structure and function of the developing pulmonary circulation after preterm birth may play an important role in hyperoxia-induced lung injury. ${ }^{23,24}$ The pulmonary vascular changes contribute to high pulmonary vascular resistance, with decreased angiogenesis and vascular surface area in a growing child. ${ }^{25,26}$ Thus, increased risk of $\mathrm{PH}$ in preterm born infants has been discussed as originating from impaired vascular growth, resulting in a limited vascular surface. Our findings may, to some extent, support this hypothesis as the risk of PH remained unaltered even after adjustments for known risk factors such as CHD, congenital diaphragm herniation, and pulmonary disease.

Studies have shown persistent airflow limitation as well as impairment of exercise capacity and systolic function of the right ventricle in adolescents and young adults following preterm birth, even after mild lung diseases. ${ }^{27-29}$ Although pulmonary function in most infants with BPD improves over time, factors related to impaired lung growth and inflammation among preterm born infants may have an impact on the development of PH later in life. Little is known about the long-term effects of altered lung development, as well as predicting infants at risk. Our study indicates that as yet unknown factors may be involved. Echocardiograms at 7 days of age and specific genetic pathways including collagen fibril organization, morphogenesis, embryonic epithelium, and regulation may predict pulmonary disease in infants. ${ }^{22,30-32}$ Introduction of molecular therapies, along with the combined effects of currently established therapies, will hopefully reduce long-term pulmonary morbidity among infants delivered preterm.

In Sweden, preterm birth occurs in 6,000 (6\%) infants each year. During the study period, infants born between 33 and 36 gestational weeks accounted for about $5.0 \%$ of all live born infants, and about $1.4 \%$ of infants were born before 33 gestational weeks. ${ }^{7}$ In our study, birth prior to 37 completed weeks was defined as preterm. Among cases retrieved from the SWEDCON registry, 29 (35.8\%) compared to $29(7.2 \%)$ of the controls were born preterm. The exposure of premature birth among the controls was in line with the expected prevalence during the study period, while this exposure was much more common among cases. This strengthens the hypothesis that exposure to premature birth increases the risk of pulmonary hypertension.

The six controls were individually matched to each case and were randomly selected by staff from the Swedish Medical Birth Register. As exposures to premature birth, CHD and BPD are rare, we choose to match six controls to each case and by this increase power to the study. In order to rule out the risk of selection bias due to differences in medical care, the cases and controls were matched by year and hospital of birth.

Survival rates for preterm born infants in Sweden during the study period increased, and about $70 \%$ of all infants with a birthweight of less than $1000 \mathrm{~g}$ were alive and discharged from hospital during the first years of the 21 st century. ${ }^{14}$ Survival rates for the study period account for cases as well as controls, and rule out the 
risk of selection bias due to survival following preterm birth.

Some studies indicate that cardiovascular malformations, such as ventricular septum defect and atrial septum defect, are more common among preterm infants than term born infants. ${ }^{33} \mathrm{CHD}$, a very heterogeneous condition, is a known risk factor for PH. Depending on the type of defect and previous repair approximately $5-10 \%$ of patients with CHD will develop pulmonary arterial hypertension. ${ }^{34}$ By adjusting for CHD, we ruled out this confounding factor in our study.

A weakness in the study was the risk of misclassification of diagnosis as many doctors contribute to the registers, and the potential bias of cases included in the SWEDCON register, as the coverage varies between regions in Sweden. SWEDCON is a national register with an increasing adherence rate to $84 \%$ of all pediatric cardiology clinics in Sweden in recent years. ${ }^{35}$

\section{CONCLUSION}

Previously, CHD, pulmonary diseases, and other factors have been linked to $\mathrm{PH}$ in children and young adults who were born preterm. By adjusting for previously known risk factors for $\mathrm{PH}$, our study indicates that new factors may play a role in the risk of developing $\mathrm{PH}$ among preterm born infants.

\section{ACKNOWLEDGMENTS}

We would like to thank the SWEDCON register and its steering committee for sharing data and we acknowledge all the pediatric cardiology doctors and nurses in Sweden.

\section{REFERENCES}

1. Abman SH. Pulmonary hypertension in children: a historical overview. Pediatr Crit Care Med 2010;11:S4-S9.

2. Bhat R, Salas AA, Foster C, Carlo WA, Ambalavanan N. Prospective analysis of pulmonary hypertension in extremely low birth weight infants. Pediatrics 2012;129:e682-e689.

3. Berkelhamer SK, Mestan KK, Steinhorn RH. Pulmonary hypertension in bronchopulmonary dysplasia. Semin Perinatol 2013;37:124-131.

4. Naumburg E, Axelsson I, Huber D, Soderstrom L. Some neonatal risk factors for adult pulmonary arterial hypertension remain unknown. Acta Paediatr 2015;104:1104-1108.

5. Franklin RCG, Anderson RH, Daniëls O, Elliott Marc MJ, Gewillig HML, Ghisla R, Krogmann ON, Ulmer HE, Stocker FP; Coding committee of the association for european paediatric cardiology. The european paediatric cardiac code: the first revision. Cardiol Young 2002;12:1-211.

6. WHO. World Health Organization Classifications. http://apps. who.int/classifications/icd10/browse/2016/en

7. The National Board of Health and Welfare. Pregnancies, Deliveries and Newborn Infants. The Swedish Medical Birth Register 1973-2009. Official Statistics of Sweden. StatisticsHealth and Medical Care. Socialstyrelsen, 2010. http://www. socialstyrelsenseregisterhalsodataregistermedicinskafodelseregis tret/inenglish

8. Lee K, Khoshnood B, Wall SN, Chang Y, Hsieh HL, Singh JK. Trend in mortality from respiratory distress syndrome in the United States, 1970-1995. J Pediatr 1999;134:434-440.

9. Liechty EA, Donovan E, Purohit D, Gilhooly J, Feldman B, Noguchi A, Denson SE, Sehgal SS, Gross I, Stevens D, et al. Reduction of neonatal mortality after multiple doses of bovine surfactant in low birth weight neonates with respiratory distress syndrome. Pediatrics 1991;88:19-28.

10. Halliday HL. Overview of clinical trials comparing natural and synthetic surfactants. Biol Neonate 1995;67:32-47.

11. Crowley P, Chalmers I, Keirse MJ. The effects of corticosteroid administration before preterm delivery: an overview of the evidence from controlled trials. $\mathrm{Br} \mathrm{J}$ Obstet Gynaecol 1990;97:11-25.

12. Ehrenkranz RA, Walsh MC, Vohr BR, Jobe AH, Wright LL, Fanaroff AA, Wrage LA, Poole K, National Institutes of Child Health and Human Development Neonatal Research Network. Validation of the National Institutes of Health consensus definition of bronchopulmonary dysplasia. Pediatrics 2005;116:1353-1360.

13. Rubaltelli FF, Bonafe L, Tangucci M, Spagnolo A, Dani C. Epidemiology of neonatal acute respiratory disorders. A multicenter study on incidence and fatality rates of neonatal acute respiratory disorders according to gestational age, maternal age, pregnancy complications and type of delivery. Italian Group of Neonatal Pneumology. Biol Neonate 1998;74:7-15.

14. Fellman V, Hellstrom-Westas L, Norman M, Westgren M, Kallen K, Lagercrantz H, Marsal K, Serenius F, Wennergren M. One-year survival of extremely preterm infants after active perinatal care in Sweden. JAMA 2009;301:2225-2233.

15. Koivisto M, Marttila R, Kurkinen-Raty M, Saarela T, Pokela ML, Jouppila P, Hallman M. Changing incidence and outcome of infants with respiratory distress syndrome in the 1990s: a population-based survey. Acta Paediatr 2004;93:177-184.

16. Jobe AH, Bancalari E. Bronchopulmonary dysplasia. Am J Respir Crit Care Med 2001;163:1723-1729.

17. Corbet A, Bucciarelli R, Goldman S, Mammel M, Wold D, Long W. Decreased mortality rate among small premature infants treated at birth with a single dose of synthetic surfactant: a multicenter controlled trial. American Exosurf Pediatric Study Group 1. J Pediatr 1991;118:277-284.

18. Berger RM, Beghetti M, Humpl T, Raskob GE, Ivy DD, Jing ZC, Bonnet D, Schulze-Neick I, Barst RJ. Clinical features of paediatric pulmonary hypertension: a registry study. Lancet 2012;379:537-546.

19. del Cerro Marin MJ, Sabate Rotes A, Rodriguez Ogando A, Mendoza Soto A, Quero Jimenez M, Gavilan Camacho JL, Raposo Sonnenfeld I, Moya Bonora A, Albert Brotons DC, Moreno Galdo A. Assessing pulmonary hypertensive vascular disease in childhood. Data from the Spanish registry. Am J Respir Crit Care Med 2014;190:1421-1429.

20. Kinsella JP, Greenough A, Abman SH. Bronchopulmonary dysplasia. Lancet 2006;367:1421-1431.

21. Bohlin K, Jonsson B, Gustafsson AS, Blennow M. Continuous positive airway pressure and surfactant. Neonatology 2008;93. 309-315

22. Mourani PM, Sontag MK, Younoszai A, Miller JI, Kinsella JP, Baker CD, Poindexter BB, Ingram DA, Abman SH. Early pulmonary vascular disease in preterm infants at risk for bronchopulmonary dysplasia. Am J Respir Crit Care Med 2015;191:87-95.

23. Perreault T. Persistent pulmonary hypertension of the newborn. Paediatr Respir Rev 2006;7:S175-S1S6. 
24. Zhang L, Yuan LJ, Zhao S, Shan Y, Wu HM, Xue XD. The role of placenta growth factor in the hyperoxia-induced acute lung injury in an animal model. Cell Biochem Funct 2015;33:44-49.

25. Baker CD, Abman SH, Mourani PM. Pulmonary hypertension in preterm infants with bronchopulmonary dysplasia. Pediatr Allergy Immunol Pulmonol 2014;27:8-16.

26. Abman SH. Bronchopulmonary dysplasia: "a vascular hypothesis”. Am J Respir Crit Care Med 2001;164:1755-1756.

27. Baraldi E, Carraro S, Filippone M. Bronchopulmonary dysplasia: definitions and long-term respiratory outcome. Early Hum Dev 2009;85:S1-S3.

28. Lewandowski AJ, Bradlow WM, Augustine D, Davis EF, Francis J, Singhal A, Lucas A, Neubauer S, McCormick K, Leeson P. Right ventricular systolic dysfunction in young adults born preterm. Circulation 2013;128:713-720.

29. Smith LJ, van Asperen PP, McKay KO, Selvadurai H, Fitzgerald DA. Reduced exercise capacity in children born very preterm. Pediatrics 2008;122:e387-e393.
30. Li J, Yu KH, Oehlert J, Jeliffe-Pawlowski LL, Gould JB, Stevenson DK, Snyder M, Shaw GM, O’Brodovich HM. Exome sequencing of neonatal blood spots and the identification of genes implicated in bronchopulmonary dysplasia. Am J Respir Crit Care Med 2015;192:589-596.

31. Li Y, Cui Y, Wang C, Liu X, Han J. A risk factor analysis on disease severity in 47 premature infants with bronchopulmonary dysplasia. Intractable Rare Dis Res 2015;4:82-86.

32. Abman SH, Mourani PM, Sontag M. Bronchopulmonary dysplasia: a genetic disease. Pediatrics 2008;122:658-659.

33. Tanner K, Sabrine N, Wren C. Cardiovascular malformations among preterm infants. Pediatrics 2005;116:e833-e838.

34. Harries C, Armstrong I. A review of the management of pulmonary arterial hypertension associated with congenital heart disease. Eur J Cardiovasc Nurs 2012;11:239-247.

35. Myndigheten för vårdanalys; 2014. Nationella kvalitetsregisters täckningsgrad. http://www.vardanalys.se 